\title{
Diagnosis and Management of Idiopathic Drug-Induced Severe Neutropenia and Agranulocytosis
}

\author{
Emmanuel Andrès ${ }^{1 *}$, Rachel Mourot-Cottet ${ }^{1}$ and Frédéric Maloisel ${ }^{2}$ \\ ${ }^{1}$ Departments of Internal Medicine B, University Hospital of Strasbourg, Strasbourg 67000, France \\ ${ }^{2}$ Department of Haematology, Saint Anne's Clinic, Strasbourg 67000, France
}

Received: August 22, 2017; Accepted: October 04 2017; Published:November 15, 2017

*Corresponding author: Emmanuel Andrès, Department of Internal Medicine, Medical Clinic B, Civil Hospital, Strasbourg University Hospital, 1 Porte de l'Hôpital, 67091 Strasbourg Cedex, France, Tel: 33-3-88-11-50-66; Fax: 33-3-88-11-62-62; E-mail: emmanuel.andres@chru-strasbourg.fr

\begin{abstract}
In this paper, we report and discuss the diagnosis and management of severe neutropenia and agranulocytosis (neutrophil count of $<$ $0.5 \mathrm{x} 109 / \mathrm{L}$ ) related to drug intake, thus considered as "idiopathic" in case of unpredictable. For practitioners and pharmacists, it is important to keep in mind that almost all classes of drugs have been implicated ("causative"), but for the majority the risk appears to be very small. This rare event (2.4 to 15.4 per million per year), remains a potentially serious adverse event of drugs due to the presence of severe deep tissue infections (e.g., pneumonia), septicaemia, and septic shock in approximately two-thirds of the patients. Recently, several prognostic factors have been identified that may be helpful when identifying frailty patients. Old age ( $>65$ years), septicaemia or shock, metabolic disorders such as renal failure, and a neutrophil count below $0.1 \times 109 / \mathrm{L}$ have been consensually accepted as poor prognostic factors for haematological recovery. In this potentially life-threatening disorder, modern management with broad-spectrum antibiotics and haematopoietic growth factors (particularly G-CSF), is likely to improve the prognosis. Thus, with appropriate management, the mortality rate of idiosyncratic drug-induced agranulocytosis is currently around 5\%.
\end{abstract}

Key words: Agranulocytosis; Neutropenia; Drugs; Infections; Antibiotics; Haematopoietic Growth Factor;

\section{Introduction}

Severe neutropenia is characterized by a profound decrease of circulating granulocytes, also called agranulocytosis in case of a neutrophil count of $<0.5 \times 109 / \mathrm{L}$ (associated or not with fever) $[1,2]$. Schultz first introduced the term "agranulocytosis" in 1922, for cases of acute and severe pharyngeal infections, associated with a lack of granulocytes in the blood in relation with drug intake. Such unpredictable event (named "idiosyncratic") is typically serious, with around $50 \%$ of cases exhibiting severe sepsis and a mortality rate of $10-20 \%$ these twenty later years $[1,2]$. As in neutropenia related to chemotherapy, modern management of such event may reduce the infection-related mortality. All practitioners may be informed and attentive of this potential life-threatening event, event in case of "daily" or "everyday" medication exposure, as: antibiotics (beta-lactams, cotrimoxazole), antithyroid drugs, neuroleptic, non-steroidal anti-inflammatory agents, and platelet aggregation inhibitors. In the present paper, we report and discuss the diagnosis and management of idiopathic drug-induced (or drug-associated) agranulocytosis.

\section{Search strategy}

A literature search was performed on the PubMed database of the US National Library of Medicine. We searched for articles published between January 2010 and February 2017, using the following key words or associations: "drug-induced neutropenia", "drug-induced agranulocytosis" and "idiosyncratic agranulocytosis"; restrictions included: English- or Frenchlanguage publications; published from Jan. 1, 2010, to Feb. 31, 2017; human subjects; clinical trials, review articles or guidelines. All of the English and French abstracts were reviewed by at least two senior researchers from our work group. American Society of Hematology educational books, textbooks of Hematology and Internal medicine, and information gleaned from international meetings were also used.

\section{Criteria for the definition}

Most, but not all cases of agranulocytosis occur as a result of exposure to drugs [3]. All drugs may be the causative agents, particularly: chemotherapy, immune modulator agents or biotherapies. Other daily drugs may be also more rarely incriminated. Such event is called "idiosyncratic druginduced agranulocytosis" or "idiosyncratic drug-associated agranulocytosis" [1]. Either the drug itself or one of its metabolites may be the causative agent. The recommended criteria for diagnosing blood cytopenias and for implicating a drug as a causative agent in neutropenia are derived from an international consensus meeting [2, 4]. These criteria are outlined in table 1. As idiosyncratic agranulocytosis is a life-threatening condition, no patient was re-challenged with the incriminated drug ("theoretical method of reference"). 
Table 1: Criteria for idiosyncratic drug-induced agranulocytosis (adapted from [1-3]) Definition of agranulocytosis:

\section{Criteria of drug imputability:}

Neutrophil count $<0.5 \times 109 / \mathrm{L} \pm$ existence of a fever and/or any signs of infection

Onset of agranulocytosis during treatment or within 7 days of exposure to the drug, with a complete recovery in neutrophil count of more than $1.5 \times 109 / \mathrm{L}$ within one month of discontiuing the drug

Recurrence of agranulocytosis upon re-exposure to the drug (this is rarely observed, as the high risk of mortality contra-indicates new administration of the drug)

Exclusion criteria: history of congenital neutropenia or immune mediated neutropenia, recent infectious disease (particularly recent viral infection), recent chemotherapy and/or radiotherapy and/or immunotherapy* and existence of an underlying haematological disease

*: Immunoglobulins, interferon, anti-TNF antibodies, anti-CD20 (rituximab)...

\section{Epidemiology}

Idiosyncratic agranulocytosis is a rare disorder. In Europe, the annual incidence of such events is between 1.6 and 9.2 cases per million populations $[2,5,6]$. In the USA, reported ranges from 2.4 to 15.4 per million per year [7]. In our experience (observational study in a French hospital), from 1996 to 2017, the annual incidence of symptomatic idiosyncratic agranulocytosis remained stable, with approximately 6 cases per million population [8]. Differences in the observed incidence may be due to different methods/inclusion criteria used in the studies published $[1,2]$. Geographic variability in incidence is related to both differences in reporting and medication usage but could also suggest genetic differences in susceptibility. Older patients are thought to be at greater risk for to drug-induced neutropenia, probably because of increased medication use [2]. As we shown below, everyday medication can be involved in such blood event. It is therefore very important to educate all practitioners, including those practicing in speciality, and pharmacist, those in hospitals or in the city. It's important to note that the incidence remains unchanged, despite the withdrawn of incriminated drugs (which carry a high risk) and increased levels of medical awareness and Pharmacovigilance [2]. This is in relation with the development of neutropenia and agranulocytosis induced by new drugs.

Table 2: Drugs implicated in the occurrence of agranulocytosis [1-3]

\begin{tabular}{|c|c|}
\hline Family drug & Drugs \\
\hline $\begin{array}{l}\text { Analgesics and nonsteroidal } \\
\text { anti-inflammatory drugs: }\end{array}$ & $\begin{array}{l}\text { Acetaminophen, Acid Acetylsalicylic (Aspirin), Aminopyrine, Benoxaprofen, Diclofenac, Diflunisal, Dipyrone, } \\
\text { Fenoprofen, Indomethacin, Ibuprofen, Naproxen, Phenylbutazone, Piroxicam, Sulindac, Tenoxicam, Tolmetin }\end{array}$ \\
\hline $\begin{array}{l}\text { Antipsychotics, hypnosedatives } \\
\text { and antidepressants: }\end{array}$ & $\begin{array}{c}\text { Amoxapine, Chlomipramine, Chlorpromazine, Chlordiazepoxide, Clozapine, Diazepam, Fluoxetine, Haloperidol, } \\
\text { Levopromazine, Mirtazapine, Imipramine, Indalpin, Meprobamate, Mianserin, Olanzapine, Phenobarbital, } \\
\text { Phenothiazines, Risperidone, Tiapride, Ziprasidone }\end{array}$ \\
\hline Antiepileptic drugs: & Carbamazepine, Ethosuximide, Lamotrigine, Phenytoin, Trimethadione, Valproic Acid (Sodium Valproate) \\
\hline Antithyroid drugs: & Carbimazole, Methimazole, Potassium Perchlorate, Potassium Thiocyanate, Propylthiouracil \\
\hline Cardiovascular drugs: & $\begin{array}{l}\text { Acid Acetylsalicylic, Amiodarone, Aprindine, Bepridil, Captopril, Coumarins, Dipyridamole, Digoxin, Flurbiprofen, } \\
\text { Furosemide, Hydralazine, Lisinopril, Methyldopa, Nifedipine, Phenindione, Procainamide, Propafenone, } \\
\text { Propanolol, Quinidine, Ramipril, Spironolactone, Thiazide Diuretics, Ticlopidine, Vesnarinone }\end{array}$ \\
\hline Anti-infective agents: & $\begin{array}{l}\text { Abacavir, Acyclovir, Amodiaquine, Atovaquone, Cephalosporins, Chloramphenicol, Chloroguanine, Chloroquine, } \\
\text { Ciprofloxacin, Clindamycin, Dapsone, Ethambutol, Flucytosine, Fusidic Acid, Ganciclovir, Gentamicin, } \\
\text { Hydroxychloroquine, Isoniazid, Levamizole, Lincomycin, Linezolid, Macrolids, Mebendazole, Mepacrine, } \\
\text { Metronidazole, Minocycline, Nitrofurantoin, Norfloxacin, Novobiocin, Penicillins, Pyrimethamine, Quinine, } \\
\text { Rifampicin, Streptomycin, Terbinafine, Tetracycline, Thioacetazone, Tinidazole, Trimethoprim-Sulfametoxazole } \\
\text { (Cotrimoxazole), Vancomycin, Zidovudine }\end{array}$ \\
\hline Miscellaneous drugs: & $\begin{array}{l}\text { Acetazolamide, Acetylcysteine, Allopurinol, Aminoglutethimide, Arsenic Compounds, Benzafibrate, } \\
\text { Brompheniramine, Calcium Dobesilate, Chloropheniramine, Cimetidine, Colchicine, Dapsone, Deferiprone, } \\
\text { Mercurial Diuretics, Famotidine, Flutamide, Gold Salts, Glucocorticoids, Glyburide, Hydroxychloroquine, } \\
\text { Levodopa, Mesalazine, Metapyrilène, Methazolamide, Metoclopramide, Olanzapine, Omeprazole, Oral } \\
\text { Hypoglycemic Agents (Glibenclamide), Penicillamine, Prednisone, Ranitidine, Riluzole, Sulfasalazine, Most } \\
\text { Sulfonamides, Sulfonylureas ,3tamoxifen, Thenalidine, Tretinoid, Tripelennamine }\end{array}$ \\
\hline
\end{tabular}




\section{Causative drugs}

For practitioners and pharmacists, it is important to keep in mind that almost all classes of drugs have been implicated ("causative"), but for the majority the risk appears to be very small (Table 2) [1, 2, 9-11]. However, for drugs such as antithyroid drugs, ticlopidine, clozapine, phenothiazines, sulfasalazine, trimethoprim-sulfametoxazole (cotrimoxazole), and dipyrone or sulfasalazine, the risk may be higher $[10,11]$. For antithyroid drugs (propylthiouracil and méthimazole), a risk of 3 per 10,000 users has been reported [1]. For ticlopidine, the risk is more than 100 -fold higher [9]. Clozapine induces agranulocytosis in almost $1 \%$ of patients, particularly in the first three months of treatment, with older patients and females being at a higher risk [11]. In our single centre cohort $(\mathrm{n}=203)$, the most frequent causative drugs are: antibiotics (49.3\%), especially ß-lactams $(n=52)$ and cotrimoxazole $(\mathrm{n}=19)$; antithyroid drugs $(16.7 \%)$; neuroleptic and anti-epileptic agents (11.8\%); antiviral agents (7.9\%); and platelet aggregation inhibitors (6.9\%), especially ticlopidine $(n=10)$ [8]. Since 1990 and 2000, no case of noramidopyrine- and ticlopidine-induced agranulocytosis was observed, respectively. Conversely, cases of idiosyncratic agranulocytosis associated with clozapine or antiviral agents were observed only since 2000 and 2005, respectively. These findings are similar to two recent reports that incriminated the same drug families $[10,12]$. Recently, several new drugs have been listed as causative agents for severe neutropenia, e.g. acyclovir, ganciclovir, lamotrigine, terbinafine or deferiprone (http://www.mhpharmacotherapy. com/0071800530/online_pdfs/24_Dipi_Web_Ch24_359374.pdf). In our cohort study, two thirds of patients received more than two drugs with a mean of three drugs, accounting for the difficulty in definitively identifying the drug responsible for the agranulocytosis. In this cohort, no over "self-medication" was documented [8]. No inappropriate prescribing, as the use of drug that pose more risk than benefit, the misuse of drugs by dose or duration, is also identified.

\section{Clinical manifestations}

Initially, symptomatic patients with idiosyncratic druginduced agranulocytosis usually present with fever, which often is the earliest and sometimes the only sign during evolution. This later is often associated with general malaise, often including chills $[1,2]$. Symptoms may appear either immediately or insidiously, depending on the time course of neutropenia development. Symptomatic patients also commonly present at discovery a non-specific sore throat, acute tonsillitis or sinusitis. More rarely, patients have first, as a not expected and brutal event, a severe deep and potentially life-threatening infection [2]. It's important to note that without medical intervention, particularly immediate antibiotics administration, natural history of agranulocytosis includes severe and potentially life-threatening infections with often signs of general sepsis and septicaemia (fever, chills, hypotension...). During the evolution, documented pneumonia (Figure 1) as well as anorectal, skin or oropharyngeal infections and septic shock were the most reported infections $[1,2,8]$. To date, classical manifestations as necrotic tonsillitis and perinea gangrene or are exceptional. Beside these "loud" manifestations, clinicians must keep in mind that the signs of these infections may be sometimes crude and atypical because of the neutropenia. Thus, it is frequent to see despite a true lung infection: no purulent sputum, few clinical sign on auscultation (few crackles), and no image on X-ray for pneumonia (Figure 2) [2]. In this situation, CT-scan may be proposed with much better results. It is notable that when antibiotics are administered prophylactically, or at the beginning of this adverse event, both the patient's complaints and the physical findings may be "masked" and fever is often the only clinical sign detected $[1,2]$. The clinical presentations recorded in our aforementioned cohort study $(\mathrm{n}=203)$ mainly included [8]: isolated fever (unknown origin) (26.3\%); septicaemia (13.9\%); documented pneumonia (13.4\%); sore throat and acute tonsillitis (9.3\%); and septic shock (6.7\%). While in hospital, $19.2 \%$ of the patients worsened clinically and exhibited features of severe sepsis, septic shock, or systemic inflammatory response syndrome (SIRS). A causative pathogen, typically Gram-negative bacilli or Gram-positive cocci (mainly Staphylococcus spp.), was isolated in $30 \%$ of cases [2]. Fungi are also involved as secondary infective agents ( $>10 \%)$, however in a few per cent of cases in regard to neutropenia related to chemotherapy. In more than 200 patients, we have observed only one case of invasive lung aspergillosis (Figure 3) and one case of mucormycosis of the maxillary sinus and the lung [8]. It is worth noting, that in elderly patients, clinical manifestations were generally more severe, with septicaemia or septic shock in at least two-thirds of patients in our experience, as we have previously published [13]. It is also the case in patients with associated morbidities as chronic cardiac failure, chronic obstructive pulmonary disease, renal failure and immune disorders. In our experience, the depth of the neutropenia impacts the severity of the clinical, manifestations [2]. At the opposite side, some patients $(<20 \%$ ) (not-well identified characteristics or profile) remained asymptomatic [1]. This supports the case for routine monitoring of blood counts in individuals receiving high-risk medications such as antithyroid drugs or ticlopidine $[1,14]$. This also supports a not consensual home management of such an event in certain patients (young, without medical history, with fever as the sole sign) [1].

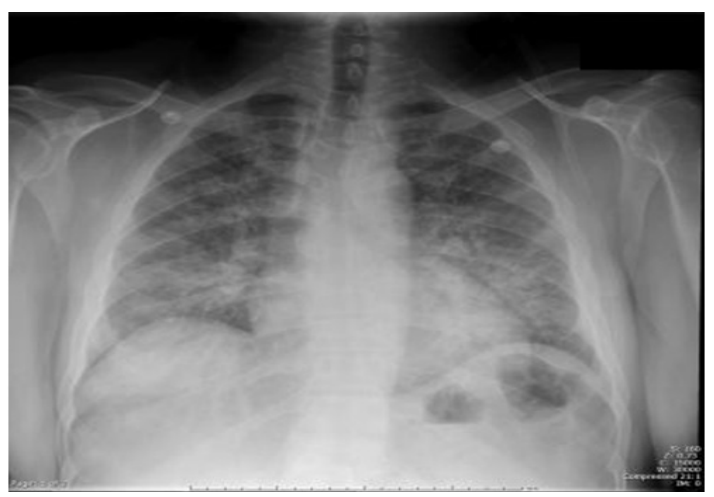

Figure1: Chest radiography in a patient with absolute neutrophil count $<0.39$ x 109/L: bilateral extensive pneumonia 


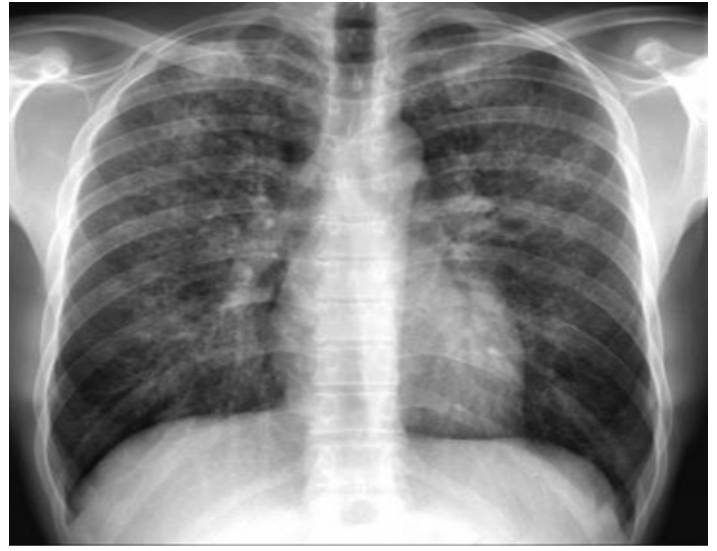

Figure 2: Chest radiography in a patient with absolute neutrophil count $<0.1$ x 109/L: "masked" pneumonia

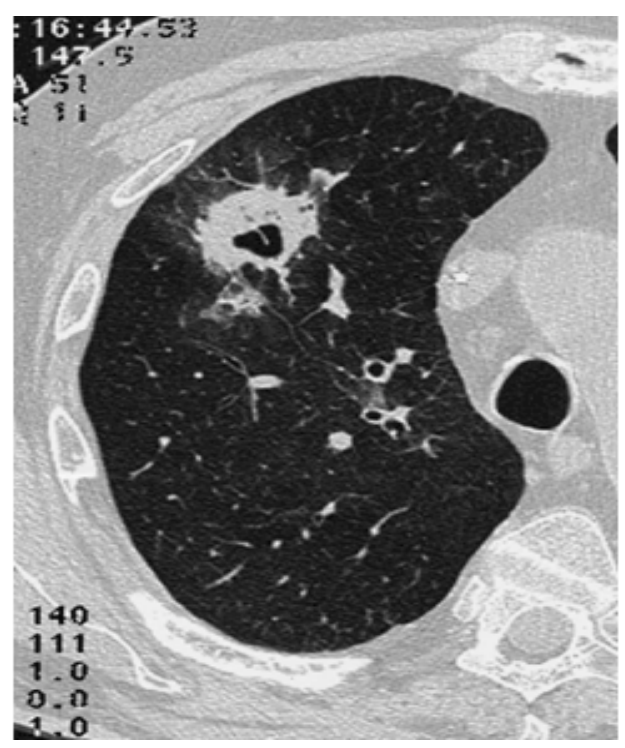

Figure 3: CT-scan in a patient with absolute neutrophil count $<0.1 \mathrm{x}$ 109/L: lung aspergillosis

\section{Differential Diagnosis}

Theoretically, acute neutropenia is classically diagnosed in a blood sample, resulting in an absolute neutrophil count of $<0.5 \times 109 / \mathrm{L},[1,2]$. In the majority of patients, the neutrophil count is under $0.1 \times 109 / \mathrm{L}$. Thus, the differential diagnosis of such acute and severe neutropenia in adults includes a limited number of conditions [2]. In fact, the main differential diagnoses include myelodysplastic syndromes and acute leukaemia. All other conditions induced moderate neutropenia, with an absolute neutrophil count between 1.5 to 0.5 x 109/L. These conditions mainly includes: neutropenia secondary to sepsis, particularly viral infections or bacterial infections (severe Gram negative infections with Salmonella sp...., tuberculosis, Brucella sp.); and neutropenia associated with hypersplenism [2]. Other, rarer differential diagnoses include neutropenia secondary to nutritional deficiencies, Felty's syndrome, systemic lupus
Erythematosus or Sjögren's syndrome [2]. In the literature, severe neutropenia (absolute neutrophil count $<0.5 \times 109 / \mathrm{L}$ ) has been shown to be attributable to drugs in 70 to $90 \%$ of cases [1]. Thus in practice, drug-induced neutropenia or agranulocytosis should be discussed routinely (considered in first) even if there is a context moving towards another condition. In this context, the clinician must keep in mind that in all cases, the patient's medication history must be carefully obtained in chronological order so that the suspected agent(s) may be identified $[1,2]$.

In our experience, bone marrow examination may not be required for all patients, but is pivotal to exclude an underlying pathology in the elderly [2]. In patients with drug-induced agranulocytosis, the bone marrow typically shows a lack of mature myeloid cells, whereas in other cases, immature cells from the myelocyte stage are preserved. This latter appearance is described as "myeloid maturation arrest" [2].

\section{Prognosis and Mortality Rate}

Drug-induced agranulocytosis usually resolves over time with supportive care and management of infection [2]. The time to neutrophil recovery has typically been reported to range from 4 to 24 days. In our aforementioned cohort study $(n=203)$, outcome was favorable in $91.6 \%$ of subjects [8]. The mean duration of haematological recovery (neutrophil count $\geq 1.5 \times 109 / \mathrm{L}$ ) is 7.8 days (Range : 2 - 20). The median duration for neutrophil count $\geq 0.5 \times 109 / \mathrm{L}$ is 6.8 days (Range : 1-24). Over the past twenty years, the mortality rate for idiosyncratic agranulocytosis was $10-16 \%$ in European studies $[1,2]$. However, this has recently fallen to $5 \%$ (Range, 2.5 to $10 \%$ ). This is likely due to improved recognition, management and treatment of the condition. The highest mortality rate is observed in frailty patients: older patients (> 65 years), with poor performance status, as well as those with several comorbidities as renal failure, chronic heart failure; septicaemia or shock at diagnosis $[2,15]$. We have recently confirmed indirectly these findings by performing a uniand multivariate analysis of factors affecting the haematological recovery, duration of hospitalisation and outcome in our cohort study [8]. In this study, bone marrow showing a lack of myeloid cells was not found to be associated with a delayed recovery. Previously, we have demonstrated that several variables were significantly associated with a longer neutrophil recovery time (> $1.5 \times 109 / \mathrm{L}$ ), as: an absolute neutrophil count of $<0.1 \times 109 / \mathrm{L}$ at diagnosis, as well as septicaemia and/or shock [16].

\section{Supportive Management}

In practice, the management of idiosyncratic drug-induced agranulocytosis begins with the immediate withdrawal of any medications, which may potentially be responsible [1, 2]. Thus, the patient's medication history must be carefully obtained in chronological order so that the suspected agent(s) may be identified. In our opinion, routine monitoring for agranulocytosis is required in some high-risk drugs, such as clozapine, ticlopidine and antithyroid drugs $[1,2]$. All cases of drug-induced neutropenia must be notified to the Pharmacovigilance centre [2]. All febrile 
patients should be admitted to hospital, without any delay [2]. It should be noted that as a result of neutrophil deficiency, both the patient's symptoms and the physical findings may be altered, and fever may be the only clinical sign $[1,2]$. Important prognostic factors resulting in an increased risk of serious complications must be systematically searched $[2,16]$. Patients with a low risk of infection, with none of the bad factors of prognosis and good performance status, should also usually be treated in hospital, unless adequate and comprehensive medical follow-up can be provided in an ambulatory setting or at home [1]. Nevertheless to date, several not frailty patients are managed in home with intensive supervision and monitoring! Concomitant measures include realization of multiple microbial samples (blood, urine, stool and sputum cultures) and aggressive treatment of confirmed or potential sepsis, as well as the prevention of secondary infections $[1,2]$. Preventive measures include good hygiene and infection control, paying particular attention to high-risk areas such as the mouth, skin and perineum [1]. Patient isolation and the use of prophylactic antibiotics (e.g. for the gastrointestinal tract) have been proposed, but their usefulness in limiting the risk of infection has not been documented or at least, has not been clinically proven [2]. The occurrence of sepsis requires prompt management, without any delay, including the administration of broad-spectrum intravenous antibiotic therapy [1, 2]. It's important to note that these recommendations are not validated specifically for idiosyncratic agranulocytosis but are based on the evidence based-medicine recommendations for the management of chemotherapy-induced neutropenia (field of oncology) [2, 3]. It's also important to keep in mind that transfusion of granulocyte concentrates should only be used in exceptional circumstances, and only then for the control of life-threatening infections with antibiotic resistance - such as perineal gangrene [2].

\section{Antibiotherapy}

The occurrence of sepsis requires prompt management, without any delay, including the administration of broadspectrum intravenous antibiotic therapy $[1,2]$. In our hospital, we commonly combine in first line therapy, new cephalosporins and quinolones or aminoglycosides [8]. Of course ureidopenicillins beta-lactam/beta-lactamase inhibitor combinations, as carbapenems, or imipenem can be safely used in these antibiotic combinations. The addition of intravenous vancomycin or teicoplanin is considered in patients at high risk of serious gram- positive infections or after 48 hours of continued fever despite first line of antibiotics with at least cephalosporins [1,2]. When an antibiotic is suspected of being the causative agent resulting in neutropenia, one should keep in mind the potential for antibody cross-reactivity, and therefore the choice of further antibiotics to be administered should be considered very carefully [1] In patients with a persistent fever despite broad-spectrum antibiotics against Gram-negative bacilli or Gram-positive cocci or systematically after 1 week of persistent fever, the addition of empirical antifungal agents should be considered, as amphotericin B or related derivates (e.g. liposomal preparation of amphotericin) and voriconazol or caspofungin [2].

\section{Usefulness Of Haematopoietic Growth Factor}

Since 1985, two-thirds of reported cases of idiosyncratic agranulocytosis have been treated with haematopoietic growth factors, especially Granulocyte-Colony Stimulating Factor (G-CSF) [17]. We do not use or recommend Granulocyte Monocyte-Colony Stimulating Factor (GM-CSF), because of lower efficiency and reported side effects as pulmonary leukostasis. To our knowledge, no data is available with pegylated G-CSF. The most recent, major studies on haematopoietic growth factors use in drug-induced agranulocytosis are described in table 3 [18-22]. In our aforementioned cohort, a faster haematological non significantly recovery (neutrophil count $>1.5$ x 109/L) was observed in the haematopoietic growth factors group: 2.1 days ( $p=0.057$ ) [8]. Nevertheless, we observed no other improvements in these patients associated with haematopoietic growth factors therapy, particularly relating to duration of antibiotherapy and hospitalization. These results do not go in the same direction as those we had previously reported [2], but are consistent with those reported in recent larger studies of haematopoietic growth factors therapy in idiosyncratic agranulocytosis patients [1]. Thus, for certain Haematologist the usefulness of haematopoietic growth factors remains controversy in such patients. To support this view, the only available prospective randomized study (based on 24 patients with antithyroid-related agranulocytosis) did not confirm the benefit of G-CSF [23]. Nevertheless, this negative result may be related to inappropriate G-CSF doses $(100-200 \mu \mathrm{g} /$ day) [2]. In our cohort study, we have established the long-term (mean follow-up > 52 months) safety of haematopoietic growth factors, in the absence of haematological adverse events such as myelodysplasia and haematological proliferative disorders [24].

Table 3: Recent studies on the use of hematopoietic growth factors in idiosyncratic drug-induced agranulocytosis (adapted from [17-22])

\section{Type of study and target population}

Systematic review of all published cases $(\mathrm{n}=492)$; All patients with idiosyncratic drug-induced agranulocytosis

Meta-analysis ( $\mathrm{n}=118)$; All patients with idiosyncratic drug-induced agranulocytosis

\section{Main results}

Treatment with haematopoietic growth factors was associated with a statistically significantly lower rate of infectious and fatal complications, in cases with a neutrophil count $<0.1 \times 109 / \mathrm{L}$

G-CSF or GM-CSF (100 to $600 \mu \mathrm{g} /$ day) reduced the mean time to neutrophil recovery (neutrophil count $>0.5 \times 109 / \mathrm{L}$ ) from 10 to 7.7 days, in cases with a neutrophil count $<0.1 \times 109 / \mathrm{L}$, and reduced the mortality rate from 16 to $4.2 \%$ 


\begin{tabular}{|c|c|}
\hline $\begin{array}{l}\text { Case control study, retrospective analysis }(\mathrm{n}=70) \text {; All patients with } \\
\text { idiosyncratic drug-induced agranulocytosis }\end{array}$ & $\begin{array}{l}\text { G-CSF and GM-CSF ( } 100 \text { to } 600 \mu \mathrm{g} / \text { day) reduced the recovery of neutrophil } \\
\text { count from } 7 \text { to } 4 \text { days, particularly in patients with a neutrophil count }<0.1 \\
\text { x 109/L }\end{array}$ \\
\hline $\begin{array}{l}\text { Cohort study, retrospective analysis }(\mathrm{n}=54) \text {; Patients with } \\
\text { idiosyncratic drug-induced agranulocytosis }>65 \text { years of age, with } \\
\text { poor prognostic factors }\end{array}$ & $\begin{array}{l}\text { G-CSF }(300 \mu \mathrm{g} / \text { day) significantly reduced the mean duration for } \\
\text { haematological recovery from } 8.8 \text { to } 6.6 \text { days }(p<0.04) \text {. G-CSF reduced the } \\
\text { global cost }\end{array}$ \\
\hline $\begin{array}{l}\text { Cohort study, retrospective analysis }(\mathrm{n}=20) \text {; Patients with } \\
\text { antithyroid drug-induced agranulocytosis and poor prognostic } \\
\text { factors }\end{array}$ & $\begin{array}{l}\text { G-CSF }(300 \mu \mathrm{g} / \text { day) significantly reduced the mean durations of } \\
\text { haematological recovery, antibiotic therapy and hospitalization from: } 11.6 \text { to } \\
6.8 \text { days, } 12 \text { to } 7.5 \text { days and } 13 \text { to } 7.3 \text { days, respectively ( } p<0.05 \text { in all cases). } \\
\text { G-CSF reduced the global cost }\end{array}$ \\
\hline $\begin{array}{l}\text { Cohort study, retrospective analysis ( } \mathrm{n}=145) \text {; All patients with } \\
\text { idiosyncratic drug-induced agranulocytosis }\end{array}$ & G-CSF shortens time to recovery in patients with agranulocytosis \\
\hline $\begin{array}{l}\text { Prospective randomized study }(\mathrm{n}=24) \text {; All patients with antithyroid } \\
\text { drug-induced agranulocytosis }\end{array}$ & $\begin{array}{l}\text { G-CSF (100 to } 200 \mu \mathrm{g} / \text { day) did not significantly reduce the mean duration } \\
\text { for haematological recovery }\end{array}$ \\
\hline
\end{tabular}

\section{Conclusions}

In conclusion, for practitioners and pharmacists, it is important to keep in mind that: (i) all drugs may be causative for idiosyncratic agranulocytosis, but mainly antibiotics (beta-lactams and cotrimoxazole), carbimazole, clozapine and ticlopidine; (ii) idiosyncratic agranulocytosis remains a potentially serious adverse event due to the frequency of severe sepsis, with pneumonia, septicaemia, and septic shock in twothirds of all hospitalized patients; (iii): old age, poor performance status, septicaemia or shock, comorbidities such as renal failure, and a neutrophil count below $0.1 \times 109 / \mathrm{L}$ have been consensually accepted as factors that impact the haematological recovery; duration of hospitalisation and the outcome; and (iv) supportive management, broad-spectrum antibiotics in case of any sepsis sign and haematopoietic growth factors as G-CSF is likely to improve the prognosis, with a currently mortality rate around $5 \%$.

\section{Acknowledgement}

No sources of funding were used to assist the preparation of this manuscript. The authors have no conflicts of interest that are directly relevant of the content of this manuscript. E. Andrès is recipient of a grant from CHUGAI, AMGEN, ROCHE, GSK, NOVARTIS but these sponsors had no part in the research or writing of the present manuscript. F. Maloisel is recipient of a grant from CHUGAI, AMGEN, ROCHE, SHIRE, GSK but these sponsors had no part in the research or writing of the present manuscript.

\section{References}

1. Andersohn F, Konzen C, Garbe E. Non-chemotherapy drug-induced agranulocytosis: A systematic review of case reports. Ann Intern Med. 2007;146(9):657-665.

2. Andrès E, Zimmer J, Mecili M, Weitten T, Alt M, Maloisel F. Clinical presentation and management of drug-induced agranulocytosis. Expert Rev Hematol. 2011;4(2):143-151. Doi: 10.1586/ehm.11.12
3. Patton WN, Duffull SB. Idiosyncratic drug-induced haematological abnormalities: incidence, pathogenosis, management and avoidance. Drug Safety. 1994;11(6):445-462.

4. Bénichou C, Solal-Celigny P. Standardization of definitions and criteria for causality assessment of adverse drug reactions. Drug-induced blood cytopenias: report of an international consensus meeting. Nouv Rev Fr Hematol. 1993;33(3): 257-262.

5. Van der Klauw MM, Goudsmit R, Halie MR, van't Veer MB, Herings RM, Wilson JH, et al. A population-based case-cohort study of drugassociated agranulocytosis. Arch Intern Med.1999;159(4):369-374.

6. Van Staa TP, Boulton F, Cooper C, Hagenbeek A, Inskip H, Leufkens HG. Neutropenia and agranulocytosis in England and Wales: incidence and risk factors. Am J Hematol. 2003;72(4):248-254.

7. Strom BL, Carson JL, Schinnar R, Snyder ES, Shaw M. Descriptive epidemiology of agranulocytosis. Arch Intern Med.1992;152(7):14751480.

8. Andrès E, Mourot-Cottet R, Maloisel F, Séverac F, Keller O, Vogel T, et al. Idiosyncratic drug-induced neutropenia \& agranulocytosis. QJM. 2017; 110(5):299-305. Doi: 10.1093/qjmed/hcw220

9. Shapiro S, Issaragrisil S, Kaufman DW, Anderson T, Chansung $\mathrm{K}$, Thamprasit T, et al. Agranulocytosis in Bangkok, Thailand: a predominantly drug-induced disease with an unusually low incidence. Aplastic Anemia Study Group. Am J Trop Med Hyg. 1999;60(4):573577.

10.Van der Klauw MM, Wilson JH, Stricker BH. Drug-associated agranulocytosis: 20 years of reporting in the Netherlands (19741994). Am J Hematol. 1998;57(3):206-211.

11. Kaufman DW, Kelly JP, Jurgelon JM, Anderson T, Issaragrisil S, Wiholm $\mathrm{BE}$, et al. Drugs in the aetiology of agranulocytosis and aplastic anaemia. Eur J Haematol. 1996;60:23-30.

12. Kelly JP, Kaufman DW, Shapiro S. Risks of agranulocytosis and aplastic anemia in relation to the use of cardiovascular drugs: The International Agranulocytosis and Aplastic Anemia Study. Clin Pharmacol Ther. 1991;49(3):330-341. Doi: 10.1038/clpt.1991.37

13. Andrès E, Mourot-Cottet R, Maloisel F, Keller O, Séverac F, Vogel T, et al. Idiosyncratic drug-induced severe neutropenia and agranulocytosis in elderly patients ( $\geq 75$ years) : a monocentric cohort study of 61 cases. Drugs Real World Outcomes. 2016;3(4):393-399. Doi:10.1007/ s40801-016-0091-4 
14. Tajiri J, Noguchi S, Murakami T, Murakami N. Antithyroid drug-induced agranulocytosis. The usefulness of routine white blood cell count monitoring. Arch Intern Med. 1990;150(3):621-624.

15. Julia A, Olona M, Bueno J, Revilla E, Rosselo J, Petit J, et al. Drug-induced agranulocytosis: prognostic factors in a series of 168 episodes. $\mathrm{Br}$ Hematol. 1991;79(3):366-371. Doi: 10.1111/j.1365-2141.1991. tb08042.x

16. Maloisel F, Andrès E, Kaltenbach G, Noel E. Prognostic factors of hematological recovery in nonchemotherapy drug-induced agranulocytosis. Haematologica. 2003;88(4): 470-471.

17. Andrès E, Maloisel F, Zimmer J. The role of haematopoietic growth factors G-CSF and GM-CSF in the management of drug-induced agranulocytosis. Br J Haematol. 2010;150(1):3-8. Doi: 10.1111/j.13652141.2010.08104.x

18.Andrès E, Kurtz JE, Martin-Hunyadi C, Kaltenbach G, Alt M, Weber JC, et al. Non-chemotherapy drug-induced agranulocytosis in elderly patients: the effects of Granulocyte Colony-Stimulating Factor. Am J Med. 2002;112(6):460-464. Doi.org/10.1016/S00029343(02)01064-1

19. Andrès E, Kurtz JE, Perrin AE, Dufour P, Schlienger JL, Maloisel F. The use of haematopoietic growth factors in antithyroid-related drug-induced agranulocytosis: a report of 20 patients. QJ Med. 2001;94(8):423-428. Doi: $10.1093 /$ qjmed/94.8.423
20.Sprikkelman A, de Wolf JTM, Vellenga E. Application of haematopoietic growth factors in drug-induced agranulocytosis: a review of 70 cases. Leukemia. 1994;8(12):2031-2036.

21. Beauchesne MF, Shalansky SJ. Nonchemotherapy drug-induced agranulocytosis: a review of 118 patients treated with colonystimulating factors. Pharmacotherapy. 1999;19(3):299-305. Doi: 10.1592/phco.19.4.299.30941

22. Ibáñez L, Sabaté M, Ballarín E, Puig R, Vidal X, Laporte JR. Use of granulocyte colony-stimulating factor (G-CSF) and outcome in patients with non-chemotherapy agranulocytosis. Pharmacoepidemiol Drug Saf. 2008;17(3):224-228. Doi: 10.1002/pds.1542

23. Fukata S, Kuma K, Sugawara M. Granulocyte colony-stimulating factor (G-CSF) does not improve recovery from antithyroid drug-induced agranulocytosis: a prospective study. Thyroïd. 1999;9(1):29-31. Doi:10.1089/thy.1999.9.29

24. Andrès E, Noel E, Maloisel F. Long-term outcome of patients treated with hematopoietic growth factors for idiosyncratic drug-induced agranulocytosis. Am J Med. 2004;116(5):354. Doi: 10.1016/j. amjmed.2003.08.026 